\title{
Complication of endoscopic ultrasound-guided celiac plexus neurolysis
}

We performed endoscopic ultrasound (EUS-)guided celiac plexus neurolysis $(\mathrm{CPN})$, because of recurrent abdominal pain resistant to analgesic drugs, in a 39year-old woman with a diagnosis of pancreatic cancer that was unamenable to surgical treatment [1-5]. No immediate complications occurred. The patient was referred 7 days later, because of persistent abdominal pain radiating through the back, associated with night fever. Transabdominal echo tomography showed a hypoechogenic area $60 \mathrm{~mm}$ in diameter with small internal hyperechogenic spots, that was located between the pancreatic body and the celiac tripod and suggestive of an abscess.

In an attempt to drain the collection we carried out EUS, using an echo endoscope with a curved transducer array connected to an echo tomography device; this showed a shortest distance of $10 \mathrm{~mm}$ between the peripancreatic collection and the gastric wall, with no intervening vessels seen at a power Doppler examination. A needle-knife was introduced through the operative channel of the echo endoscope to puncture the collection (Figure 1). At the end of the procedure, we introduced ceftazidime $1 \mathrm{~g} / 10 \mathrm{ml}$, and estimated that the collection had been reduced to approximately $30 \mathrm{~mm}$ in diameter (Figure 2).

The results of bacteriological examination demonstrated the presence of Citrobacter freundii and Pseudomonas aeruginosa, both sensitive to imipenem. Transabdominal echo tomography performed 4 days later demonstrated the complete disappearance of the fluid collection, and this was confirmed a further 5 days later by upper abdominal computed tomography (CT). Transabdominal ultrasound was done weekly in the next 3 months of follow-up and showed no recurrence of peripancreatic fluid collection.

Many authors consider CPN to be a technique that can be routinely performed as an outpatient procedure, rarely necessi-

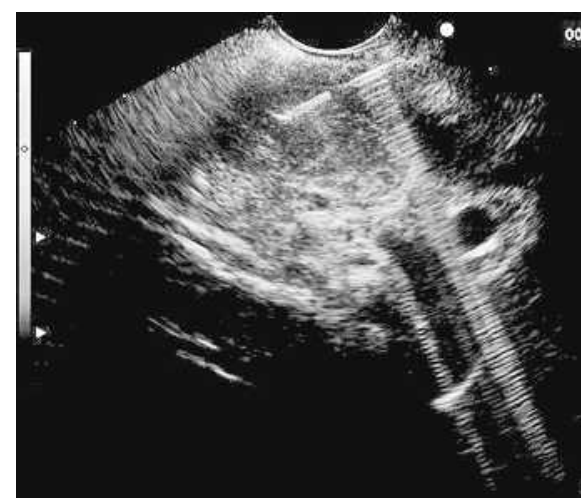

Figure 1 Puncture of the peripancreatic fluid collection, under endoscopic ultrasound

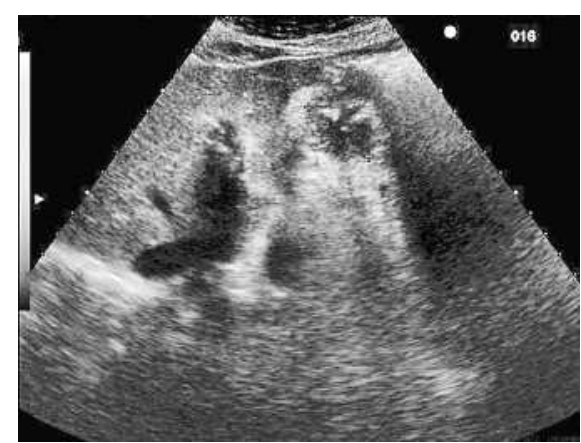

Figure 2 Estimation of the size of the collection at the end of the procedure.

tating hospitalization. However, our experience with this new complication may suggest that patients should be admitted into hospital for EUS-CPN, with the aim of administration of broad-spectrum antibiotic therapy, both before and after the procedure, to prevent complications such as the abscess described here.

Endoscopy_UCTN_Code_CPL_1AL_2AC

\footnotetext{
N. Muscatiello ${ }^{1}$, C. Panella ${ }^{2}$, L. Pietrini ${ }^{2}$, P. Tonti ${ }^{1}$, E. Ierardi ${ }^{2}$

${ }^{1}$ Gastroenterology Unit, Ospedali Riuniti, Foggia, Italy
}

2 Gastroenterology Section, Department of Medical Sciences, University of Foggia, Foggia, Italy.

\section{References}

${ }^{1}$ Plancarte R, Velasquez R, Patt R. Neurolytic blocks of the sympathetic axis. In: Patt RB, (ed). Pain. Philadelphia: Lippincott 1993: 377-425

2 Wiersema MJ, Wiersema LM. Endosonography-guided celiac plexus neurolysis. Gastrointest Endosc 1996; 44: 656-662

${ }^{3}$ Gunaratnam NT, Sarma AV, Norton, Wiersema MJ. A prospective study of EUS-guided celiac plexus neurolysis for pancreatic cancer pain. Gastrointest Endosc 2001; 54: 316-324

${ }^{4}$ Eisenberg E, Carr DB, Chalmers TC. Neurolytic celiac plexus block for treatment of cancer pain: a meta-analysis. Anesth Analg 1995; 80: 290-295

${ }^{5}$ Levy MJ, Wiersema MJ. EUS-guided celiac plexus neurolysis and celiac plexus block. Gastrointest Endosc 2003; 57: 923 -930

\section{Corresponding Author}

\section{N. Muscatiello, M.D.}

Gastroenterology Unit

Viale Pinto

Foggia 7110

Italy

Fax: $\quad+39-881-733870$

E-mail: nmuscatiello@libero.it 